\title{
Self-Tuning Pid Neural Network Controller to Control Nonlinear Ph Neutralization in Waste Water Treatment
}

\author{
Hendra Cordova ${ }^{1}$, Andry Fitra Wijaya ${ }^{1}$
}

\begin{abstract}
The conventional PID control (linear) is popular control scheme that is used in almost $\mathrm{pH}$ control at waste water treatment process. $\mathrm{pH}$ model with respect to titration liquid flow rate has been known to be intrinsically difficult and nonlinear, especially when the process is conducted to non-linear range $\mathrm{pH}$ reference $(\mathrm{pH} \mathrm{4-8})$, the settling time reach a long time. Therefore in this paper the nonlinear controller with self-tuning PID scheme is performed handle pH by training a neural-network based on backpropagation error signals. The $\mathbf{p H}$ process model is combination between CSTR (Continuous Stirred Tank Reactor) linear dynamic with $\mathrm{H}_{3} \mathrm{PO}_{4}, \mathrm{HF}, \mathrm{HCl}, \mathrm{H}_{2} \mathrm{~S}$ flow rate and nonlinear static electro neutrality (wiener process model). The simulation result has a good and suitable performance under several tests (set-point and load change). The simulation result show the $\mathrm{pH}$ control system can follow the change of $\mathbf{p H}$ set-point and load with the average steady state error 0.00034 . The settling time achieved at 50 second faster than conventional PID controller scheme.
\end{abstract}

Keywords- pH Neutralization, PID Controller, Backpropagation training, Neural Network

\section{INTRODUCTION}

$\mathrm{P}$ neutralization plays an important part in several chemical processes, pharmaceutical, wastewater treatment and biotechnology. The $\mathrm{pH}$ process exhibits severe nonlinear and time varying behavior and therefore cannot be controlled with a controller based a linear control algorithm like PID controller [1]. So far, many different approaches to dealing controlling $\mathrm{pH}$ with control algorithm were presented. [2] devised a neural PID controller method in which a neural network is trained on the basis of control errors and tuning parameter of the PID controller can obtain. [3], [4], [5], [6] used self-tuning technique to adjust PID parameters on-line. However this was based on the assumption that process to be controlled is linear. The application to control the real $\mathrm{pH}$ plant is done by [7], [8], but the result is proper in just fixed $\mathrm{pH}$ and performance degradation occur if the $\mathrm{pH}$ change given. [9] were modeled based on the reaction between a strong basic solution and strong acid and a digital PI control algorithm was used as the controller with no dead time. On this model, and indirect adaptive backstepping controller is designed by combining a backsteppping controller and the recursive prediction error method. According to several control scheme which studied by any researcher above, the Neural Network is one of compromising and popular technique to

Manuscript received August 11, 2007, revised April 3, 2008

Hendra C. And Andry F.W. are with Departement of Physics Engineering, FTI, Institut Teknologi Sepuluh Nopember, Surabaya, INDONESIA handle and reached a good performance in modeling and $\mathrm{pH}$ control. Among them have the same difficulties, more sensitive to error action, so the actuator control valve based mechanical component must respond more often than before. It caused much component process for long period will have a little bit lifetimes. On the other hand, the programming code more complicated including many algorithm identification (with neural network or adaptive), parameter estimation, recursive least square and controller structure design [10]. In this paper, the objective is to control and maintain the $\mathrm{pH}$ in neutralization and various $\mathrm{pH}$ reference change by manipulating a strong base stream flow rate using direct backpropagation neural networks algorithm. The identification is not required the inverse modeling. The neural only just training of error and control signal to determine the best PID controller parameters automatically that will system more robust and stable and the computer calculation program is simpler too, because the time consumption for learning or neural network training algorithm need just little time.

\section{THE NONLINEAR PH NEUTRALIZATION PROCESS}

The data models are based on process at PT. Petrokimia Gresik [11]. It has effluent waste process unit to neutralize of the waste product before flowing into river. The schematic $\mathrm{pH}$ neutralization process control block diagram based on P\&ID SA unit contain $\mathrm{pH}$ adjusting Tank 1 or reactor tank (TK661), the lime tank (TK 6622) that is used to control the $\mathrm{pH}$ value and coagulation tank (TK 6612) presented below:

The $\mathrm{pH}$ closed control system that is used in this paper consist of $\mathrm{pH}$ sensor, controller and control valve to flow the limestone fluid according the control signal $u$ from controller. Actually, the $\mathrm{pH}$ control is done manually by open and closes the valve from lime tank under $\mathrm{pH}$ sample observation (laboratories). Therefore it require a long time (about 2 days), while waste and process which thrown remain to walk or take place. As mentioned above, this is a reason to design a $\mathrm{pH}$ control system. There are five pipe (waste fluid) flow in the reactor tank from the unit plant before waste product treatment unit, SA Plant and Aux Boiler Blow-Down, Gypsum Plant Waste Water, Run off and Permeated Water and $\mathrm{ALF}_{3}$ Plant Waste Water. A dynamic model of the $\mathrm{pH}$ neutralization process is obtained from component material balance (see appendix) and the equilibrium relationship under assumption 
of perfect mixing, constant vessel volume $V$, and so on are proposed by [12] and related as follows:

$$
\begin{aligned}
& V \frac{d x a}{d t}=q a C a-(q a+q b) x a \\
& V \frac{d x b}{d t}=q b C b-(q a+q b) x b
\end{aligned}
$$

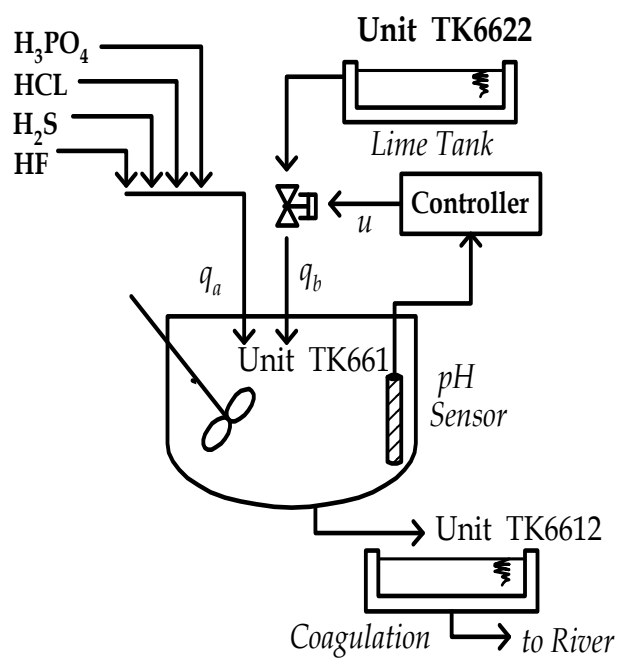

Fig. 1. pH Neutralization Process

where $\mathrm{Ca}, \mathrm{Cb}$ is the concentration of effluent stream and acid solution $(\mathrm{CaOH}), q a, q b$ is the flow rate of the influent stream, and $V$ is the volume of the mixture in the CSTR (continuous stirred tank reactor). The answer or solution of equation 1 and 2 are not achieving the $\mathrm{pH}$ values directly, and this is a problem how to determine the concentration of $\mathrm{H}^{+}$. Based on process schematic figure 1 the reaction between influent stream and titrating stream can be represented as,

$$
\begin{aligned}
& \mathrm{H}_{3} \mathrm{PO}_{4(a q)} \rightarrow 3 \mathrm{H}_{(a q)}^{+}+\mathrm{PO}_{4(a q)}^{3} \\
& \mathrm{HCL}_{(a q)} \rightarrow \mathrm{H}_{(a q)}^{+}+\mathrm{CL}_{(a q)}^{-} \\
& \mathrm{HF}_{(a q)} \rightarrow \mathrm{H}_{(a q)}^{+}+\mathrm{F}_{(a q)}^{-} \\
& \mathrm{H}_{2} \mathrm{~S}_{(a q)} \rightarrow 2 \mathrm{H}_{(a q)}^{+}+\mathrm{S}_{(a q)}^{2-} \\
& \mathrm{Al}(\mathrm{OH})_{3(a q)} \rightarrow \mathrm{Al}_{(a q)}^{3+}+3 \mathrm{OH}_{(a q)}^{-} \\
& \mathrm{Ca}(\mathrm{OH})_{2(\mathrm{aq})} \rightarrow \mathrm{Ca}_{(a q)}^{2+}+2 \mathrm{OH}_{(\mathrm{aq})}^{-} \\
& \mathrm{H}_{2} \mathrm{O}_{(a q)} \rightarrow \mathrm{H}_{(a q)}^{+}+\mathrm{OH}_{(a q)}^{-}
\end{aligned}
$$

The equilibrium constants for the reaction are calculated based on equation 3.a to 3.g are determined as follow,

$$
\begin{aligned}
K a_{1} & =\frac{3\left[\mathrm{H}^{+}\right]\left[\mathrm{PO}_{4}^{3-}\right]}{\left[\mathrm{HPO}_{4}^{3}\right]} \\
K a_{2} & =\frac{\left[\mathrm{H}^{+}\right]\left[\mathrm{F}^{-}\right]}{[\mathrm{HF}]} \\
K a_{3} & =\frac{2\left[\mathrm{H}^{+}\right]\left[\mathrm{S}^{-}\right]}{\left[\mathrm{H}_{2} \mathrm{~S}\right]} \\
K w & =\left[\mathrm{H}^{+}\right]\left[\mathrm{OH}^{-}\right]
\end{aligned}
$$

where $K a_{1}$ is dissociation constant of $\mathrm{H}_{3} \mathrm{PO}_{4}, K a_{2}$ is the dissociation constant of $\mathrm{HF}, K_{a 3}$ is dissociation constant of
$\mathrm{H}_{2} \mathrm{~S}$ and $K_{w}$ is the dissociation of water at $25^{\circ} \mathrm{C}$. The influent of $\mathrm{HCl}$ (strong acid) and $\mathrm{Ca}(\mathrm{OH})_{2}$ as strong base which fully dissociates and hence the dissociation constant are equal to zero. The chemical equilibrium is modeled using the concept of reaction invariant proposed by reference [13]. For this system, two reactions invariant are involved for each stream. Based on the electroneutrality condition, the sum of the ionic charge in the solution must be zero. Therefore we have,

$$
\begin{aligned}
& {\left[\mathrm{H}_{2} \mathrm{PO}_{4}^{-}\right]\left[\mathrm{HPO}_{4}^{2-}\right]\left[\mathrm{PO}_{4}^{3-}\right]\left[\mathrm{F}^{-}\right]\left[\mathrm{HS}^{-}\right]\left[\mathrm{Cl}^{-}\right]\left[\mathrm{OH}^{-}\right]=} \\
& {\left[\mathrm{Ca}^{2+}\right]\left[\mathrm{H}^{+}\right]}
\end{aligned}
$$

From the equation 1 and $\mathrm{d} 2, x a$ is a charge-related quantity and $x b$ is the concentration of the calcium ion can be defined as,

$$
\begin{aligned}
x a= & {\left[\mathrm{H}_{3} \mathrm{PO}_{4}\right]\left[\mathrm{H}_{2} \mathrm{PO}_{4}^{-}\right]\left[\mathrm{HPO}_{4}^{2-}\right] } \\
& {\left[\mathrm{PO}_{4}^{3-}\right]\left[\mathrm{H}_{2} \mathrm{~S}\right]\left[\mathrm{HS}^{-}\right]\left[\mathrm{Cl}^{-}\right] } \\
x b= & {\left[\mathrm{Ca}^{+}\right] }
\end{aligned}
$$

These invariants are independent of the extent of the reaction. A relation between hydrogen ion concentration and reaction invariant can be rewritten using equation 4 through 10 to give equation below,

$$
\begin{aligned}
& x a\left[\frac{\frac{K a_{1}}{\left[H^{+}\right]}}{1+\frac{K a_{1}}{\left[H^{+}\right]}}+\frac{\frac{K a_{2}}{\left[H^{+}\right]}}{1+\frac{K a_{2}}{\left[H^{+}\right]}}+\frac{\frac{K a_{3}}{\left[H^{+}\right]}}{1+\frac{K a_{3}}{\left[H^{+}\right]}}+1\right]+ \\
& +x b+\frac{K w}{\left[H^{+}\right]}-\left[H^{+}\right]=0
\end{aligned}
$$

Actually, the $\mathrm{pH}$ value is not defined as a hydrogen ion concentration but as ion activity. However, it can be assumed that the ion activity is same as the ion concentration for the infinitely diluted solution. Hence, the $\mathrm{pH}$ value can be logarithm of the hydrogen ion concentration determined using the above equations and the negative if $x a$ and $x b$ are known. The equation 11 is called static nonlinear equation (equation without derivative component) and can be rewritten,

$$
\begin{aligned}
-\left[H^{+}\right]^{5} & +a_{1}\left[H^{+}\right]^{4}+a_{2}\left[H^{+}\right]^{3}+ \\
& +a_{3}\left[H^{+}\right]^{2}+a_{4}\left[H^{+}\right]-a_{5}=0
\end{aligned}
$$

where,

$$
\begin{aligned}
a_{1}= & x b-x a-k a_{1}-k a_{2}-k a_{3} \\
a_{2}= & {\left[2 *(-x a) *\left(k a_{1}+k a_{2}+k a_{3}\right)\right]+} \\
& +\left[x b *\left(k a_{1}+k a_{2}+k a_{3}\right)\right]-k w \\
& -\left[k a_{1} * k a_{2}+k a_{2} * k a_{3}+k a_{1} * k a_{3}\right] \\
a_{3}= & {\left[-3 * x a *\left(k a_{1} * k a_{2}+k a_{2} * k a_{3}+k a_{1} * k a_{3}\right)\right] } \\
& +\left[x b *\left(k a_{1} * k a_{2}+k a_{2} * k a_{3}+k a_{1} * k a_{3}\right)\right] \\
& -\left[k w *\left(k a_{1}+k a_{2}+k a_{3}\right)-k a_{1} * k a_{2} * k a_{3}\right] \\
a_{4}= & {\left[4 *(-x a) * k a_{1} * k a_{2} * k a_{3}\right]+} \\
& +\left[x b * k a_{1} * k a_{2} * k a_{3}\right] \\
& -\left[k w *\left(k a_{1} * k a_{2}+k a_{2} * k a_{3}+k a_{1} * k a_{3}\right)\right] \\
a_{5}= & k w * k a_{1} * k a_{2} * k a_{3}
\end{aligned}
$$

The $\mathrm{H}^{+}$determined using the equation 12 for $x a$ and $x b$ given, than relation can find the $\mathrm{pH}$ value $(\mathrm{pH}=-\log$ $\left(\left[\mathrm{H}^{+}\right]\right)$. The difficulty to solve static equation 12 is 
caused the variable of $\mathrm{H}^{+}$is polynomial in order 5 . Much software in recent today can helpful to determine this root, for example Matcad or Matlab. The $\mathrm{pH}$ values can be found directly after the $\mathrm{H}^{+}$is achieved.

\section{PID SEL-FTUning CONTROLLER With NeURAL NETWORK (PIDNNC)}

Overall structure of the Neural PID controller is given in figure 2 proposed in this paper used multilayer feed forward network in which set-point, past plant outputs and past controller commands are introduced as input patterns as see below :

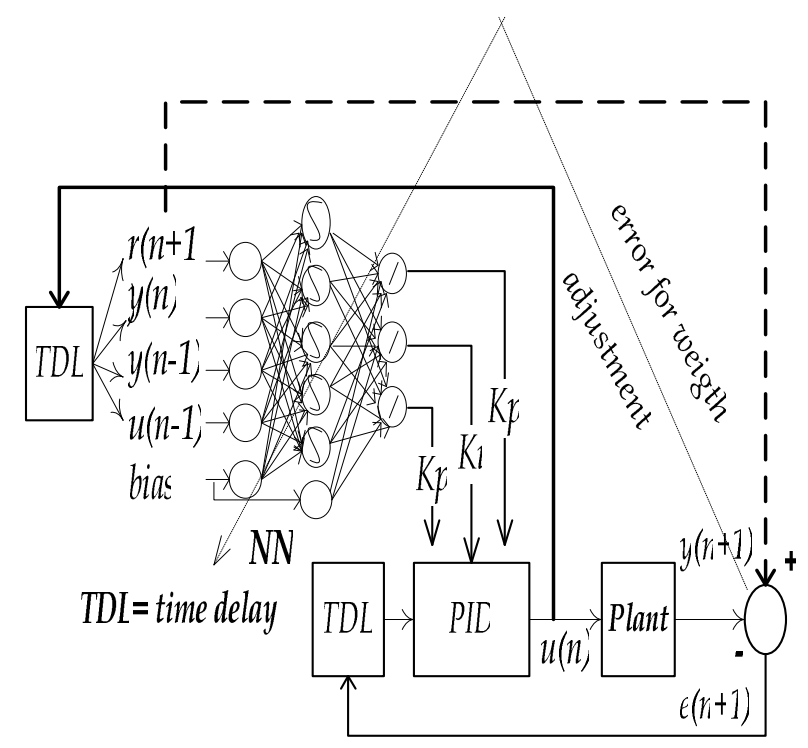

Fig. 2. The structure of Neural Network PID Self Tuning Control (PIDNNC)

At first, the output layer produces values of $P\left(K_{p}\right), I\left(K_{I}\right)$ and $D\left(K_{D}\right)$ by arbitrarily initialized weights. Those values are used as tuning parameters of the PID controller and the controller gives control command $u$ based on the difference between the set point and the plant output. The control error defined by the difference between the actual plant output $y$ and the set point is back-propagated by the learning rules and the networks is trained to generate appropriate tuning parameters in order to reduce the control error. The velocity form of a PID controller is given by,

$$
\begin{aligned}
u(n)= & u(n-1)+K_{p}(e(n)-e(n-1))+ \\
& K_{I} e(n)+K_{D}(e(n)-2 e(n-1)+e(n-2))
\end{aligned}
$$

The velocity form does not need a nominal value of controller output $u$ as that in the position form. The controller output is given by control errors $e(n), e(n-1)$ and $e(n-2)$ and values of $K_{p}, K_{I}$ and $K_{D}$ from a learned neural network. In the present neural network values of $r(n+1)$, $y(n), y(n-1) \ldots$ and $u(n-1) \ldots$, bias are fed into the layer and tuning parameters $P\left(K_{p}\right), I\left(K_{I}\right)$ and $D\left(K_{D}\right)$ are obtained from output layer in figure 3 . The structure of neural network is,

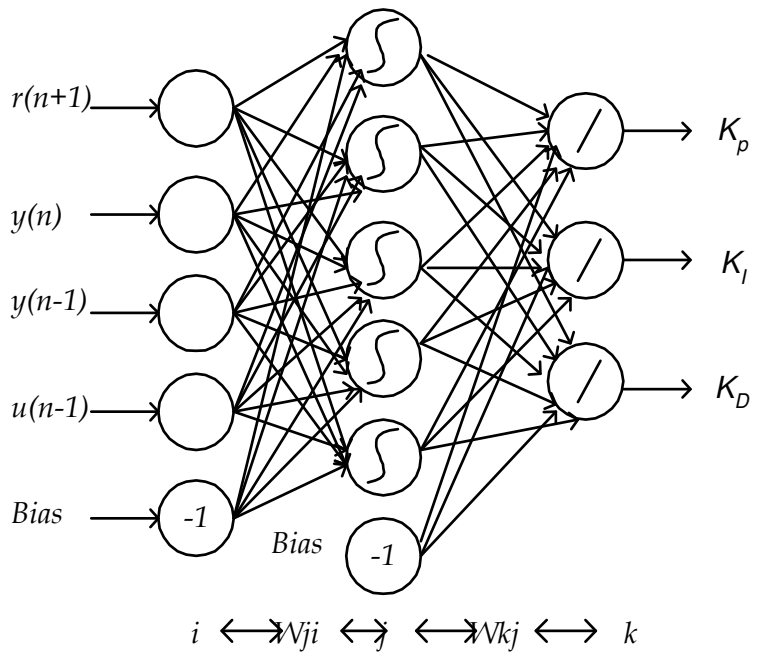

Fig.3. The neural network structure

According to figure 3 for neural network in this paper the definition each layer is,

$$
\begin{aligned}
& n e t_{j}=\Sigma w_{j i} \cdot \text { in }_{i}, \text { out }_{j}=f_{1}\left(\text { net }_{j}\right) \\
& \text { net }_{k}=\Sigma w_{k j} . \text { out }_{j}, \text { out }_{k}=f_{2}\left(\text { net }_{k}\right)
\end{aligned}
$$

With one hidden layer bias (-1) is introduced into the last node and bipolar sigmoid function (equation 21) is used as activation function. The better [14] proposed and optimal form of sigmoid function so that convergence during the learning procedure is guaranteed according to systems dynamics and formulated below,

$$
f_{1}\left(n e t_{j}\right)=\frac{2}{1+\exp \left(-n e t_{j}\right)}-1
$$

The function for the output layer is denoted by subscript $k$ is $f_{2}\left(\right.$ net $\left._{k}\right)=C_{k}$ net $t_{k}$, with $C_{k}=$ constant and the same activation function as in equation 16 . In the beginning of learning it's cannot know trained values of tuning parameters in advance and so we introduced a linear-type activation function which different from sigmoid function. In an error-back-propagation algorithm the cost function $J$ (denoted by $E$ ) is defined as the squared sum of the difference between the desired output $\left(\right.$ Target $\left._{k}\right)$ and the output obtained from the output layer $\left(\right.$ out $\left._{k}\right)$,

$$
E=\frac{1}{2} \sum_{k}\left(T \arg e t_{k}-y_{k}\right)^{2}
$$

The weight correction method to minimize the cost function is based the error in equation 17 propagate to input layer if the error target can't meet the goal. The equation to weight output update $\left(\Delta w_{j l}\right)$ as write below,

$$
\Delta w_{j k}(n)=-\eta \frac{\partial E}{\partial w_{j k}}+\alpha \cdot \Delta w_{j k}(n-1)
$$


Using chain-rule method [15] the equation 18 is proposed to weight update is given by,

$$
\frac{\partial E}{\partial w_{j k}}=\frac{\partial E}{\partial y_{k}} \frac{\partial y_{k}}{\partial y_{-} i n_{k}} \frac{\partial y_{-} i n_{k}}{w_{j k}}
$$

To faster the training computation for neural training is used by modification of equation 19 as see below,

$$
\begin{aligned}
& \Delta v_{i j}(n)=-\eta \frac{\partial E}{\partial v_{i j}}+\alpha \cdot \Delta v_{i j}(n-1) \\
& \frac{\partial E}{\partial v_{i j}}=\frac{\partial E}{\partial z_{j}} \frac{\partial z_{j}}{\partial z_{-} i n_{j}} \frac{\partial z_{-} i n_{j}}{\partial v_{i j}}
\end{aligned}
$$

The learning rate $(\eta)$ and the momentum $(\alpha)$ are the parameters that can take to avoid the local minimum in training phase. Its value is determined by trial error, but any researcher proposed takes between 0 and 1 . The controller training is also used the error-back-propagation algorithm, by take the definition $r(n)$ is the set-point or reference value and $y(n)$ is the plant output, the error for controller is $e(n)=r(n)-y(n)$ and from equation 17 the performance index is written by $E=\frac{1}{2} e(n)^{2}$. The term $\partial E / \partial w_{j k}$ in equation 19 can be rewritten as transformed equation by the chain rule to updated the weight and bias as follow,

$$
\begin{aligned}
& \frac{\partial E}{\partial w_{j k}(n-1)}=-e(n) \frac{\partial y(n)}{\partial w_{j k}(n-1)} \\
& \frac{\partial y(n)}{\partial w_{j k}(n-1)}=\frac{\partial y(n)}{\partial u(n-1)} \frac{\partial u(n-1)}{\partial w_{j k}(n-1)} \\
& \frac{\partial u(n-1)}{\partial w_{j k}(n-1)}=\frac{\partial u(n-1)}{\partial y_{k}(n-1)} \frac{\partial y_{k}(n-1)}{\partial w_{j k}(n-1)}
\end{aligned}
$$

$\frac{\partial E}{\partial w_{j k}(n-1)}=-e(n) \frac{\partial y(n)}{\partial u(n-1)} \frac{\partial u(n-1)}{\partial y_{k}(n-1)} \frac{\partial y_{k}(n-1)}{\partial w_{j k}(n-1)}$

The $\partial y k(n-1) / \partial w k j(n-1)$ term in equation 23 is determined and given by equation below,

$$
\frac{\partial y_{k}(n-1)}{\partial w_{j k}(n-1)}=\left[\frac{\partial y_{1}(n-1)}{\partial w_{j k}(n-1)}, \frac{\partial y_{2}(n-1)}{\partial w_{j k}(n-1)}, \frac{\partial y_{3}(n-1)}{\partial w_{j k}(n-1)}\right]
$$

where $\partial y_{1}(n-1)=K_{p}, \partial y_{2}(n-1)=K_{I}$, and $\partial y_{3}(n-1)=K_{D}\left(K_{p}, K_{I}\right.$ and $K_{D}$ are proportional, integral and derivative gain). The PID controller is also update (tuning) to feed the proper signal control by change the best parameter controller in the form $\frac{\partial u(n-1)}{\partial y_{k}(n-1)}$

term. Begin the chain rule method is used to train and update the controller for self-tuning term, it describe by equation below,

$$
\begin{aligned}
& \frac{\partial u(n-1)}{\partial y_{k}(n-1)}=[e(n-1)-e(n-2), e(n-1), \\
& e(n-1)-2 e(n-2)+e(n-3)]
\end{aligned}
$$

The term of $\frac{\partial y(n)}{\partial u(n-1)}$ can be obtained from input and output plant. The weight initialization is not used random number as usual researches do to train a neural network. The reason is caused that the error between set-point and controlled signal must lie in -1 to 1 range or $100 \%$ to $-100 \%$, so for suppressing the error signal this paper take a half value. The computer code simulation program is also based on equation 17,26 and 27 to create the proper parameter of PID controller.

\section{RESUlT AND DisCUSSION}

The first simulation is determined the best neural network architectures. As mentioned above the $\mathrm{pH}$ control and learning procedure run in the same time, its mean the control action is directly forced to final control element during learning. The experiment is separated in two ways, the $\mathrm{pH}$ control without load change and disturbances absent, the second test is $\mathrm{pH}$ control with load (disturbance) change. All the simulation was compared with PID scheme only [11].

\section{A. The Initialization Tuning of PID Controller}

The PID tuning that was used in this paper proposed by Ziegler-Nichols (ZN). The step input (open valve $5 \%$ to $10 \%$ ) is injected to the $\mathrm{pH}$ process, the tuning scheme is given by figure below,

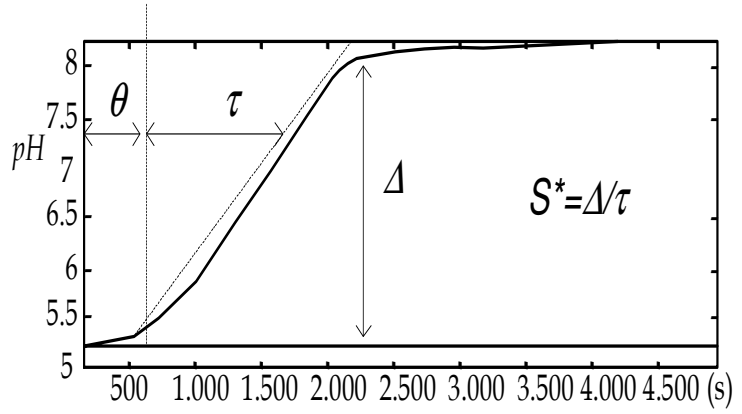

Fig. 4. The ZN Tuning procedure with open-loop or reaction curve method

The parameters PID controller are calculated based the figure 4 with proportional gain $\mathrm{K}_{\mathrm{P}}\left(\frac{1.2}{\theta S^{*}}\right)=0.2$, Integral Time $\mathrm{T}_{\mathrm{I}}(2 \theta)=0.02$ and Time Derivative $\mathrm{T}_{\mathrm{D}}$ $(0.5 \theta)=0.005$. This parameter is used to run and the first parameter PID for neural networks training and testing in the controlling $\mathrm{pH}$ neutralization. The parameter combinations for the best neural network learning are 10 nodes in the input layer, 30, 3 nodes in the hidden and input layers, its parameters will make the neural reach the desired error. A learning rate $(\eta) 0.5$ and momentum $(\lambda) 0.9$ were used and the sampling time is 1 second in all simulation.

\section{B. Fixed pH set-point without load (base flow rate) change}

The $\mathrm{pH}$ control simulation comes into two ways, with or without load present or change. The load (disturbance) $q a$ is flow of acid stream from disposal. 
In Figure 5, the regulated $q_{b}$ started at $15 \mathrm{~m}^{3} / \mathrm{hr}$, but upon passing the neutralization $\mathrm{pH} 6$ (dot line), 7 and 8 (dash line) dropped slowly to the value that stoichiometrically neutralized the wastewater stream. A decrease in $q_{b}$ results in faster neutralization time and lesser $q_{b}$. Initially, as shown in figure 5(b), oscillation occurs because of in appropriate PID tuning parameters. The proportional gain $\left(K_{p}\right)$ increase to close by slowly the control valve fed the base flow faster but at the end $\mathrm{pH}$ reach the reference the flow have constant value (look figure 5(b) dash line for $\mathrm{pH} 8$ and dot line for 6 ), this indicate the better (stable) performance occur in all $\mathrm{pH}$ control and also for integral $\left(K_{I}\right)$ and derivative $\left(K_{D}\right)$ term.

The $\mathrm{pH}$ control design is measured by qualitative parameters in time and percentage. The rise time $\left(t_{r}\right)$ is the time required for the response to come within the $\pm 5 \%$ the ultimate value (reference or set-point). The settling time $\left(t_{s}\right)$ is required for the response to come $2-5 \%$ from the reference point (steady state error, Ess). Table 1 shows the fixed set-point qualitative performance, as can see the all parameter PIDNNC better than PID.

TABLE 1

PERFORMANCE INDEX FIXED PH 6, 7, AND 8

\begin{tabular}{|c|c|c|c|c|}
\hline $\begin{array}{c}\text { Control } \\
\text { Type }\end{array}$ & $\begin{array}{c}\text { Settling } \\
\text { time } t_{s} \\
(s)\end{array}$ & $\begin{array}{c}\text { Rise } \\
\text { time } t_{r} \\
(s)\end{array}$ & $\begin{array}{l}M_{p} \\
(\%)\end{array}$ & Ess \\
\hline \multicolumn{5}{|c|}{ pH set-point 6} \\
\hline PID & 46 & 266 & 2.49 & $8.7 .10^{-5}$ \\
\hline PIDNNC & 5 & 90 & 2.49 & $7.7 \cdot 10^{-5}$ \\
\hline \multicolumn{5}{|c|}{ pH set-point 7} \\
\hline PID & 90 & 1,873 & 4.12 & $6.9 .10^{-5}$ \\
\hline PIDNNC & 53 & 1,523 & 0.96 & $7.7 .10^{-5}$ \\
\hline \multicolumn{5}{|c|}{ pH set-point 8} \\
\hline PID & 721 & 3,610 & 0.97 & $7.3 \cdot 10^{-5}$ \\
\hline PIDNNC & 708 & 1,107 & 0.17 & $5.5 .10^{-5}$ \\
\hline
\end{tabular}

\section{Fixed pH set-point with disturbance}

The PID controllers were tested using the feed disturbance sequence of acid flow $\left(q_{a}\right)$ as regulators at fixed set points

PID control with parameter $\left(K_{p}, K_{I}\right.$ and $\left.K_{D}\right)$ did fine self tuning (figure $6 \mathrm{c}$ ) and reduce the overshoot or oscillation (figure 6a) for any fixed set-point given with the manipulated variable alternating between zero and full range (figure 6b). The oscillation occurs at the beginning figure 6 and reduces at the end. Figure $6 \mathrm{~d}$ is the load or disturbance from acid flow. Figure 7 is simulation result with the load present in sequence form. Figure $7 \mathrm{a}$. looks the $\mathrm{pH}$ output have small oscillation (compare with figure $6 a$ ).

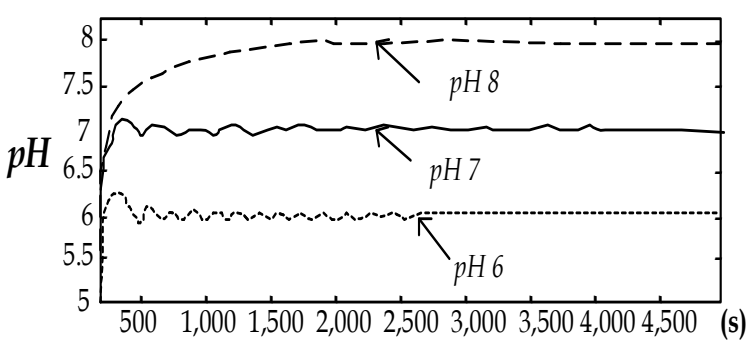

(a)
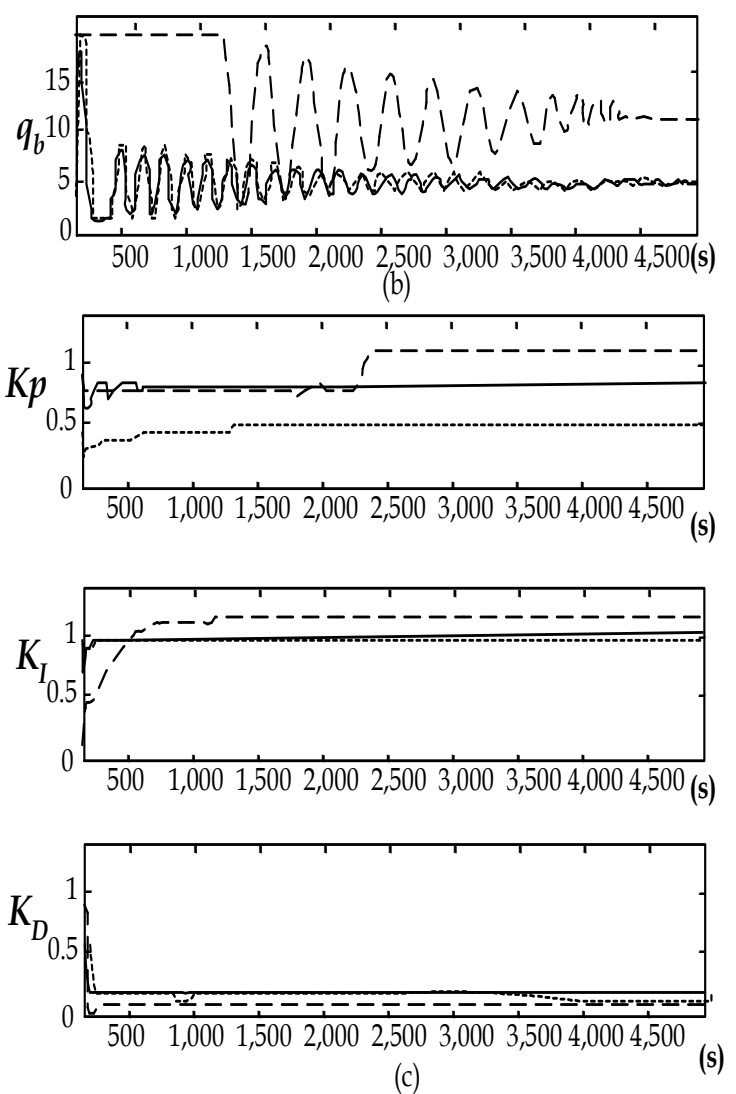

Figure 5. The fixed pH set-point 6, 7 and 8 without load change (a). $\mathrm{pH}$ output (b). Base Flow (c). PID parameter with PIDNNC

It because the load or disturbance acid flow in figure $7 \mathrm{~d}$ has a closer period time than $6 \mathrm{~d}$, so the control signal by flowing the base flow is not different in each iteration (Figure 7b). It also followed by three parameters of PID control, the value is not slightly different than the fixed set-point in $\mathrm{pH}$ control. The performance $\mathrm{pH}$ control with PIDNNC is performing a good output. The significant oscillation at the first come load occur but reduced in the steady state area, and the $\mathrm{pH} 7$ or neutral condition achieve.

\section{Set-point tracking $p H$ reference change}

The next simulation is set-point tracking performance. The results described here are for PIDNNC which tuned for tested at set-point 6 to 7 or 8 and these results are indicative of the results for controller tuned and tested at other set-point. Figure 8 the $\mathrm{pH}$ set-point change started at $7,8,7,6$, and 7 for the end of $\mathrm{pH}$ value. The better to reach for $\mathrm{pH}$ output with PIDNNC in the first time $\mathrm{pH}$ reference (figure 8a). 
The maximum changes in the control output (it also flow from valve actuator) are $\pm 20 \mathrm{~m}^{3} / \mathrm{hr}$. The control output in the response to the rising $\mathrm{pH}$ change. Every set-point change, the control signal in base flow in figure $8 \mathrm{~b}$ is change to make a proper flow until the $\mathrm{pH}$ reach each setpoint. The proportional PIDNNC tuned to appropriate signal to come the valve with suitable action (figure $8 \mathrm{c}$ ). According to PIDNN scheme, every set-point change the controller must change automatically (self-tuning) its parameter. The derivative term in figure $8 \mathrm{~d}$ like another set-point simulation does not have the different value, it happen because the steady state error or offset is faster, so the integral and derivative term in PIDNNC is not near a big constant. Any researchers choose only PI term to control $\mathrm{pH}$. This reason is the valve must open and closed to tracking the set-point change. The PIDNNC control work well due to controller tuning automatically. The all simulation gives the $2-5 \%$ for steady state error.

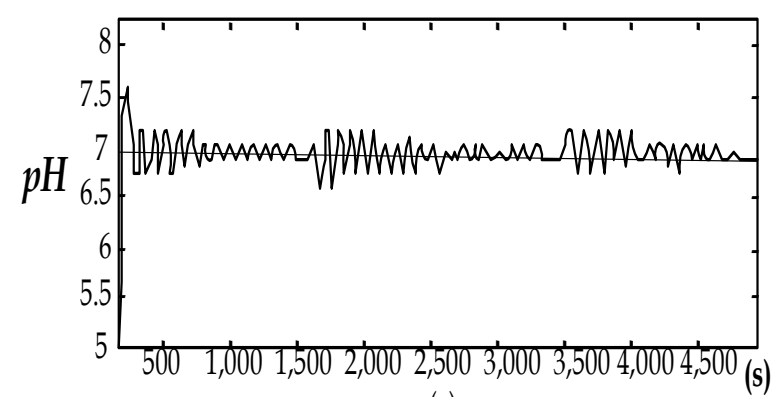

(a)

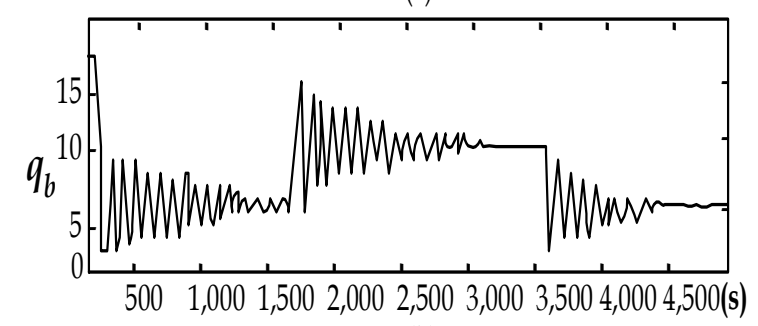

(b)

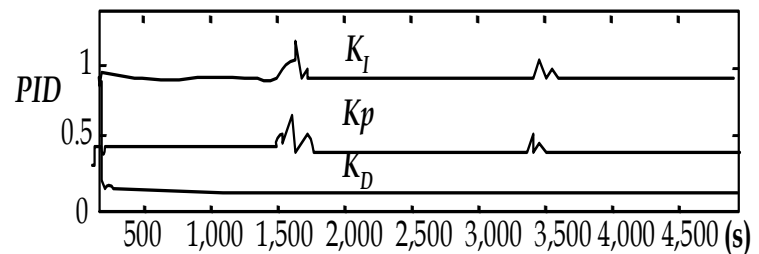

(c)

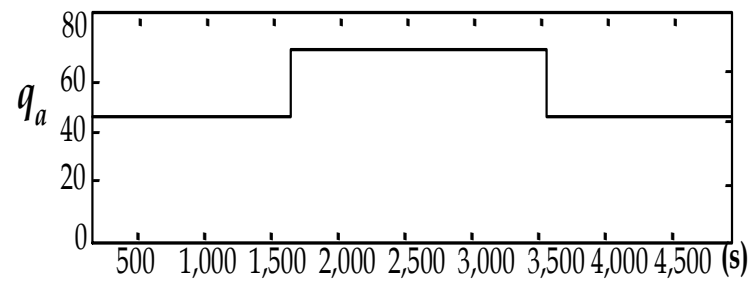

(d)

Fig. 6. pH 7 response with PIDNNC and load step (disturbance) present (a). pH output (b). Base Flow (c) PID Parameter (d) Acid load (disturbance) flow (qa)

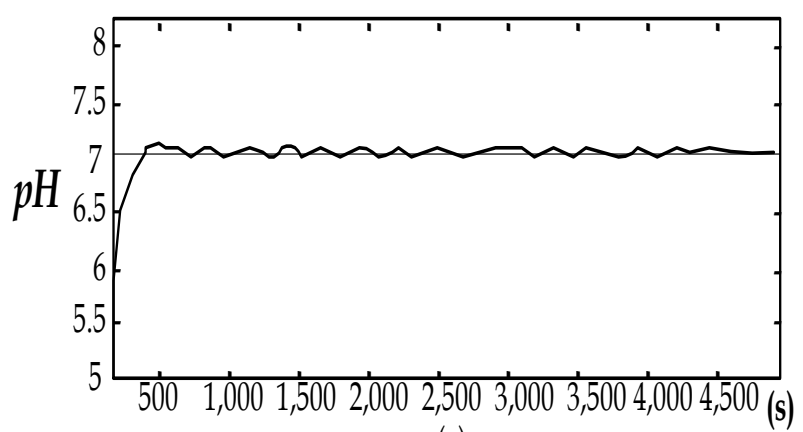

(a)

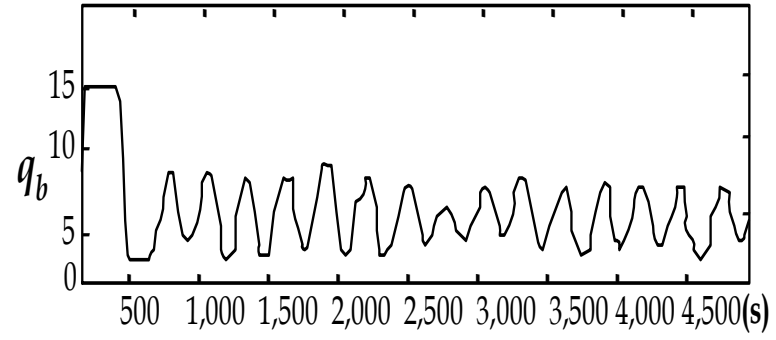

(b)

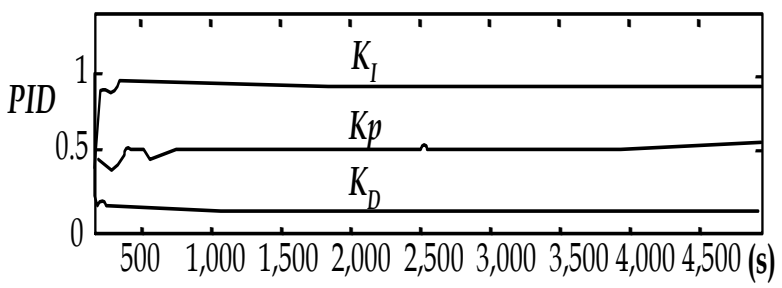

(c)

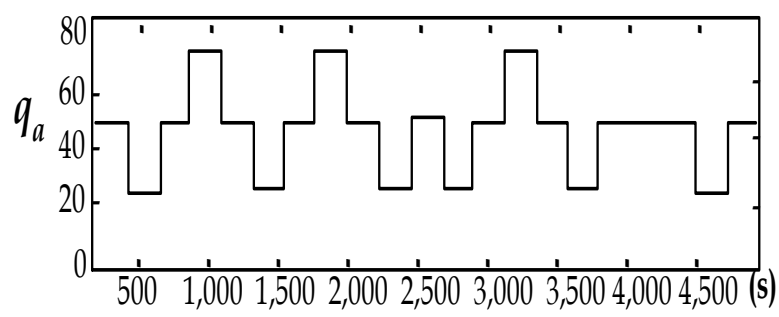

(d)

Fig.7. pH 7 response with PIDNNC and load sequence (disturbance) present (a). pH output (b). Base Flow (c) PID Parameter (d) Acid load (disturbance) flow (qa)

\section{CONCLUSION}

In this paper a Neural Network Self-Tuning PID control is proposed to handle a unique nonlinear $\mathrm{pH}$ neutralization process. In this scheme, parameters fine PID tuning is automatically updating by back propagation neural network method. The PIDNNC will choose the control action according to set-point and $\mathrm{pH}$ area. The simulation results satisfactory performing to achieving the $2 \%-5 \%$ steady state error or the pH 7 (neutral) can be obtained. The test for load or disturbance present in several set-point are also well done. 


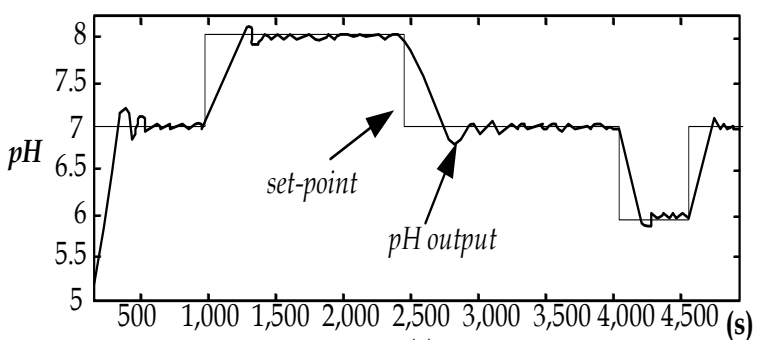

(a)

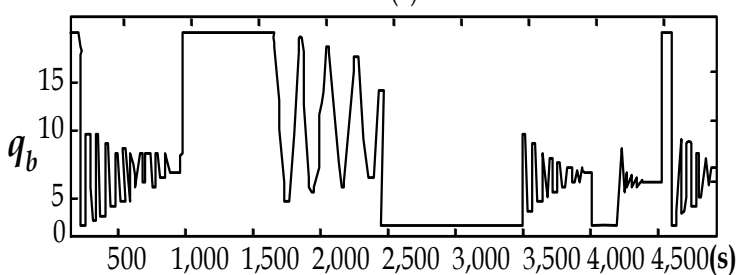

(b)

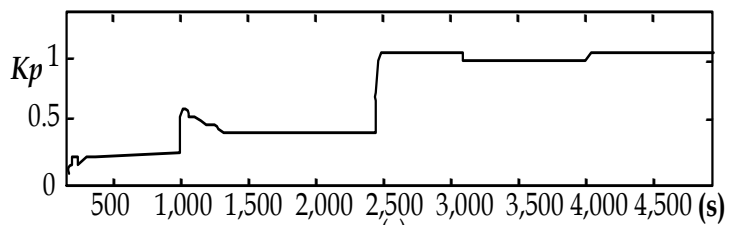

(c)

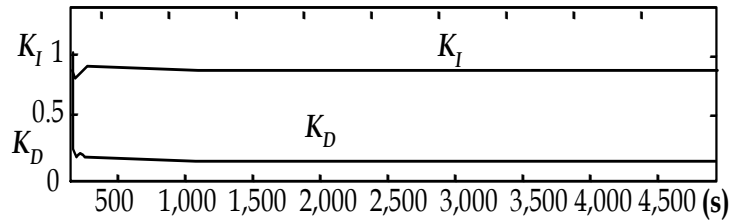

(d)

Fig. 8. Tracking pH set-point change from 6 to 8 with PIDNNC (a). pH output (b). Base Flow (c) Proportional PID (d) Integral and derivative PID Controller

\section{REFERENCES}

[1] Besharati, R, A., Lo, W, W., Tsang, K, M., "Self-tuning PID Controller Using Newton-Raphson Method", IEEE Transaction On Industrial Electronic, Vol. 44, no.5, pp. 432-440. 2001.

[2] Yeong-Koo, Y., Kwon, T., Process Design and Control: “A Neural PID Controller for The $\mathrm{pH}$ Neutralization Process.", Industrial Chemical Engineering, Vol. 20, no. 3, pp. 978-984. 2001.

[3] Boling., J,M., Seborg., D,E., Hespanha., J,P., "Multi-Model Adaptive Control of a Simulated $\mathrm{pH}$ Neutralization Process," Elsevier Science., Vol. 3. no. 2. pp. 240-250. 2006.

[4] Cordova, H., "PID Control Systems Design to pH Neutralization by Neural Network Inverse Model Optimization at PT PetrokimiaGresik," Prosiding Seminar FTI-ITS: Deindustrialisasi Nasional: Ancaman Terhadap Pengembangan Daya Saing Global, hal. 2022. 2005 .

[5] Cordova, H., "The Application of Early Warning System for Monitoring and Control pH Water Based On Auto-Switch Algorithm," Prociding International Seminar and Disaster for Early Warning Systems PSB-ITS, 4-5 March, pp.10-13. 2005.

[6] Chen, J., Cheng, Y-C., Yea, Y., "Multiloop PID Controller Design using Partial Least Squares Decoupling Structure," Korean Journal Chemical Engineering, Vol.22. no2, pp.173-185a. 2005

[7] Cordova, H., "Prototipe Kontroler PID Self-Tuning Menggunakan Algoritma Auto-Switch Berbasis Margin Fasa dan Penguatan pada Proses Penetralan pH Larutan Campuran $\mathrm{NaOH}$ dan HAC," Laporan Akhir DIKS, LPPM-ITS. 2003.

[8] Cordova, H., "PID Self-Tuning Based on Auto-Switch Algorithm to Control pH Neutralization Process," Jurnal Industri, FTI-ITS, Vol. 3, hal.3-6. 2004
[9] Ishak., A,A., Hussain., M,A., "Modelling and Control Studies of Waste Water Treatment Process.," Proceeding to Brunei International Conference on Engineering \& Technology, Bandar Seri Begawan, 9- 11 Oct. 2001, pp. 221-231.

[10] Cordova, H., "Prototipe Kontroller Intelligent Self-Tuning PID pada Proses Penetralan $\mathrm{pH}$ dengan Metode Penalaan Newton-Rhapson," Laporan Akhir DIKS, LPPM-ITS. 2006.

[11] Yoo, A., Lee, T. C., Yang, D. R., "Experimental Simultaneous State and Parameter Identification of $\mathrm{pH}$ Neutralization Process Based on and Extended Kalman Filter," Korean Journal Chemical Engineering, Vol. 21, no. 4, pp. 753-760. 2004.

[12] Gómez, J.C., Jutan, A. and Baeyens, E., "Wiener Model Identification and Predictive Control of a $\mathrm{pH}$ Neutralization Process," IEEE Proceedings on Control Theory and Applications, Vol. 151, no. 3, pp. 329-338, May, USA. 2004.

[13] Gufftafson, T.K, and Waller, K.V., "Dynamic Modeling and Reaction Invariant Control pH," Chemical Engineering Science, Vol.38, pp.389-398. 1983.

[14] Kim, D,K., Yang, D, R., "Control of pH Neutralization Using Simulation Based Dynamic Programming," Korean journal Chemical Engineering., Vol. 21, no. 5, pp. 942-949. 2004.

[15] Loh, A, P., Looi, K, O., Fong, K, F., "Neural Network Modeling and Control Strategies for a $\mathrm{pH}$ Process," Journal of Process and Control, Vol. 5 no. 6, pp. 3445-3450. 2000.

\section{APPENDIX}

The parameter that is used in neutralization tank figure 1 presented below.

Reaction Tank (TK 661)

Tank Volume

Number of input, output pipe

Flow rate pipe $1\left(\mathrm{H}_{3} \mathrm{PO}_{4}\right)$

Flow rate pipe 2(HF)

Flow rate pipe $3(\mathrm{HCl})$

Flow rate pipe $4\left(\mathrm{H}_{2} \mathrm{~S}\right)$

Titration Flow rate

Fluid inputs

\section{Transmitter (pH Sensor)}

Type

Output signal

Scale range

Repeatability

Min. Source for driving

Minimum Scale

: 67,800 liter

: 4,1

: $119,800 \mathrm{~kg} / \mathrm{hr}$

$: 2,400 \mathrm{~kg} / \mathrm{hr}$

: $40,606 \mathrm{~kg} / \mathrm{hr}$

: $8,000 \mathrm{~kg} / \mathrm{hr}$

: Max $14.5 \mathrm{~m}^{3} / \mathrm{hr}$

: $\mathrm{H}_{3} \mathrm{PO}_{4}, \mathrm{HF}, \mathrm{HCl}$,

$\mathrm{H}_{2} \mathrm{~S}$, Solid

: Coaxial Cable

: 4-20 mA DC

: $0-14 \mathrm{pH}$

: $0.05 \mathrm{pH}$

: $13 \mathrm{~V} \mathrm{DC}$

$: 0.2 \mathrm{pH}$

\section{Control Valve}

Scattering

Back ring

Flow Liquid

: TEF/CARBON

: SUS 316

: Max $14.5 \mathrm{~m}^{3} / \mathrm{H}$

Normally

Pressure

$\mathrm{m}^{3} / \mathrm{H}$

: $\mathrm{P}_{1} 1.2 \mathrm{~kg} / \mathrm{cm}^{2}$

$\mathrm{P}_{2} 0.8 \mathrm{~kg} / \mathrm{cm}^{2}(\Delta \mathrm{P}$

$0.4 \mathrm{~kg} / \mathrm{cm}^{2}$ )

Fluid

Temperature

: Lime Milk

Visc

: $50^{\circ} \mathrm{C}$

Potitioner

: $5 \mathrm{CP}$

Function
: Air to Open

: partial equal percentage 